\title{
Effects of elevated temperature on a tungsten alloy at high strain-rate
}

\author{
Ezio Cadoni ${ }^{1, *}$, Matteo Dotta $^{1}$, and Daniele Forni ${ }^{1}$ \\ ${ }^{1}$ DynaMat SUPSI Laboratory, University of Applied Sciences and Arts of Southern Switzerland, Via \\ Catenazzi 23, 6850 Mendrisio, Switzerland.
}

\begin{abstract}
The effects of elevated temperature at high strain rate of a commercial tungsten alloy were investigated. The tests were carried-out at high strainrate (from 850 to 2200 1/s) by means of a Split Hopkinson Tension Bar device on round specimens having diameter and gauge length of $2 \mathrm{~mm}$ and $5 \mathrm{~mm}$, respectively. The thermal conditions were obtained by means of a water-cooled induction heating system on the specimen mounted on the SHTB. The dependence of ultimate tensile strength on temperature was found to decrease, while the failure strain increased with temperature. The strain rate linearly growths with the temperature.
\end{abstract}

\section{Introduction}

The tungsten alloys are two-phase composite materials combining the advantageous properties of the tungsten phase and the matrix phase. They possess outstanding physicochemical properties such as high density, high strength, high hardness, good corrosion resistance, high thermal conductivity and wear resistance. Thanks to these characteristics they are widely used in numerous engineering applications in aerospace, machining. Many studies were dedicated to their high strain rate behaviour [1-3], and to the temperature effect [4-7] on mechanical characteristics. This study presents the dynamic tensile behaviour of a commercial tungsten alloy. These alloys are frequently subjected to harsh regimes of strain-rate and often combined with elevated temperature. The main objective of this experimental study is to determine the mechanical response of a commercial tungsten alloy when subjected to high strain-rate in tension at elevated temperature. The tests were carried-out at high strainrate (from 850 to 2200 1/s) by means of a Split Hopkinson Tension Bar (SHTB) device on round specimens having diameter and gauge length of $2 \mathrm{~mm}$ and $5 \mathrm{~mm}$, respectively. The thermal conditions were obtained by means of a water-cooled induction heating system on the specimen mounted on the SHTB.

\section{Material and specimens}

The material used in the current study is a commercial tungsten alloy characterised by highdensity $\left(\rho=16^{\prime} 925 \mathrm{~kg} / \mathrm{m}^{3}\right)$ with the chemical composition reported in Table 1 . The high strain-rate tests were performed on a round specimen having a diameter of $2 \mathrm{~mm}$ and gauge

\footnotetext{
*e-mail: ezio.cadoni@supsi.ch
} 
Table 1. Chemical composition of the commercial Tungsten alloy in wt.\%.

\begin{tabular}{lllll}
\hline $\mathrm{C}$ & $\mathrm{Co}$ & $\mathrm{Ni}$ & $\mathrm{O}$ & $\mathrm{W}$ \\
\hline 4.20 & 3.79 & 7.98 & 2.59 & Balanced \\
\hline & & & & \\
\hline
\end{tabular}

Figure 1. Specimen geometry for dynamic test (left) and quasi-static test (right).

length of $5 \mathrm{~mm}$. For the quasi-static tests the specimen had same diameter but longer gauge length $(15 \mathrm{~mm})$ as shown in Fig. 1. The specimen ends had a M5 fillet for the connection to the testing machines.

\section{Experimental set-up}

\subsection{Quasi-static regime}

The reference tests under quasi-static condition $\left(0.001 \mathrm{~s}^{-1}\right)$ were conducted on a Zwick/RoellZ50 universal testing machine (with $50 \mathrm{kN}$ maximum load bearing capacity) under strain control by means of high precision displacement transducer (with $0.3 \mu \mathrm{m}$ resolution), see Figure 2a. The tests were performed on specimen with diameter and gauge length of $2 \mathrm{~mm}$ and $15 \mathrm{~mm}$, respectively. In Figure $2 \mathrm{~b}$ are reported the quasi-static results in terms of stress versus strain curves as well as are indicated elastic modulus $(E)$, proof strength $\left(R_{0.2}\right)$, ultimate tensile stress $\left(R_{m}\right)$, uniform strain $\left(\epsilon_{u}\right)$, fracture stress $\left(f_{f}\right)$, fracture strain $\left(\epsilon_{f}\right)$, reduction of area $(Z)$ and modulus of resilience and toughness $\left(W_{u}\right.$ and $\left.W_{f}\right)$. This tungsten alloy behaves as a quasi-perfect elastic-plastic material even if shows a very limited elongation and brittle failure. In this regime it shows high repeatability [8].

\subsection{High strain-rate regime}

In order to study the high strain-rate behaviour of this Tungsten alloy a Split Hopkinson Tensile Bar (SHTB) $([9,10])$ was used. This apparatus is composed by two circular straight high strength steel bars with a diameter of $10 \mathrm{~mm}$ and a length of 9 and $6 \mathrm{~m}$ ([11-13]). The longer bar is used partially used $(6 \mathrm{~m})$ as a pretensioned bar and the rest $(3 \mathrm{~m})$ as input bar. The second bar is used as output bar. The tungsten alloy specimen is screwed in the input and output bars. By pulling the pretensioned bar by means of a hydraulic jack it is possible to store elastic energy in it and rules the testing velocity as a function of the load amplitude. Both input and output bars are instrumented with semiconductor strain gauges able to measure the incident $\left(\epsilon_{I}\right)$, reflected $\left(\epsilon_{R}\right)$ and transmitted $\left(\epsilon_{T}\right)$ pulses acting on the cross section of the specimen. By applying the one-dimensional elastic plane stress wave propagation theory the engineering value of stress (1), strain (2) and strain-rate (3) are obtained in function of time:

$$
\begin{aligned}
& \sigma_{e}(t)=E_{0} \cdot \frac{A_{0}}{A} \cdot \epsilon_{T}(t) \\
& \epsilon_{e}(t)=-\frac{2 C_{0}}{L} \int_{0}^{t} \epsilon_{R}(t)
\end{aligned}
$$


a)

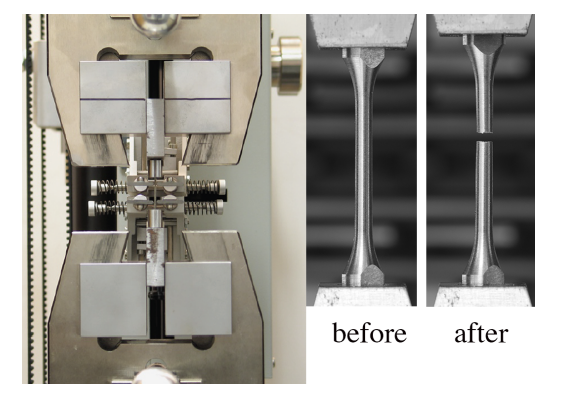

b)

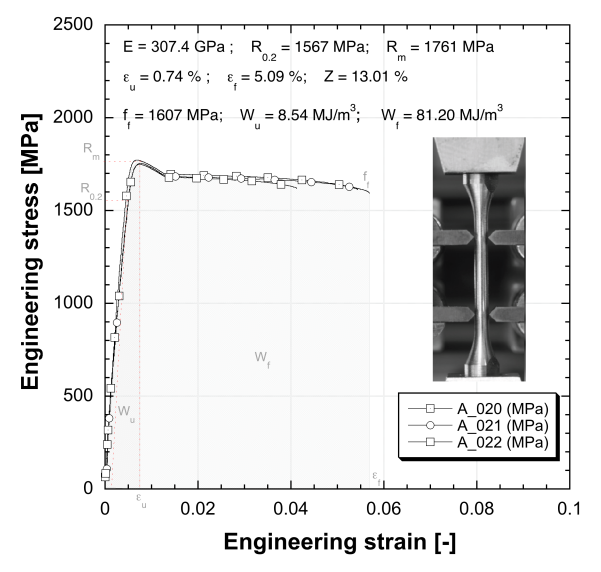

Figure 2. Quasi-static testing: a) set-up; b) results.

$$
\dot{\epsilon}_{e}(t)=-\frac{2 C_{0}}{L} \cdot \epsilon_{R}(t)
$$

The tests at elevated temperatures $[14,15]$ have been carried out equipping the SHTB with an Ambrell compact EASYHEAT induction water-cooled heating system with maximum power of $2.4 \mathrm{~kW}$ (see Figure 3a). By means of this non-contact induction heating is possible to supply energy only to the specimen gauge-length (see Figure $3 \mathrm{~b}$ ) with precise power control with $25 \mathrm{~W}$ resolution. The specimens were heated at a constant heating rate of about $3{ }^{\circ} \mathrm{C} / \mathrm{s}$ to the set temperature $\left(800^{\circ} \mathrm{C}, 900^{\circ} \mathrm{C}, 1000^{\circ} \mathrm{C}\right.$ and $\left.1100^{\circ} \mathrm{C}\right)$.

Three target strain-rates were set at $850 \mathrm{~s}^{-1}, 1400 \mathrm{~s}^{-1}$ and $2200 \mathrm{~s}^{-1}$ obtained by imposing, at room temperature, a preload of $26 \mathrm{kN}, 35 \mathrm{kN}$ and $50 \mathrm{kN}$, respectively.

During the tests the signals from strain-gauges were acquired by a HBM-Gen2 data acquisition system while the specimens were filmed at high speed by a fast camera IDT- MotionPro Y4-S3 at 43kfps.

Figure $4 \mathrm{a}$ shows how the initial conditions were kept constant. In fact, the input signals are the same for all testing temperature.

The elastic modulus at high temperature has not been measured. It can be supposed a linear decrement with increasing the temperature. Observing the strain rate evolution in function of the temperature a linear trend is noted. The strain rate can be evaluated as:

$$
\dot{\epsilon}_{T}=\dot{\epsilon}_{20^{\circ} \mathrm{C}}+\alpha \cdot T
$$

where: $\dot{\epsilon}_{T}$ is the strain rate at the temperature $T ; \dot{\epsilon}_{20}{ }^{\circ} \mathrm{C}$ is the strain rate at room temperature; $\alpha=0.417$ for this alloy. 
a)

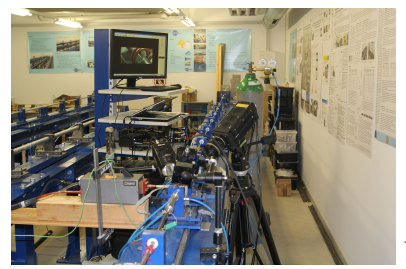

b)

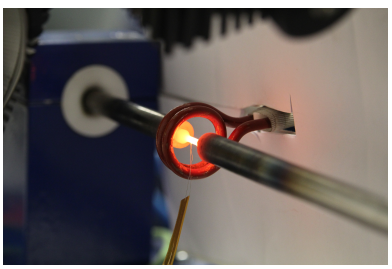

Figure 3. Dynamic testing set-up (a); Sample at elevated temperature in dynamic test (b).

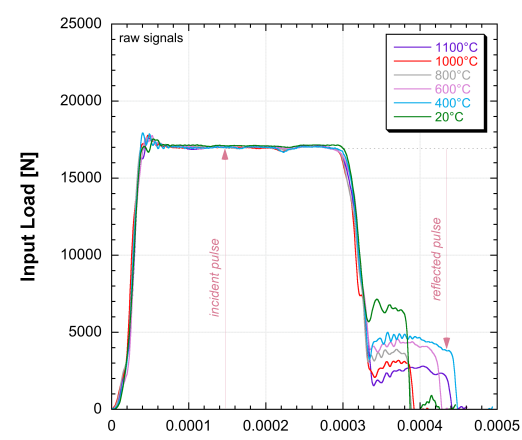

a)

Time [s]

b)

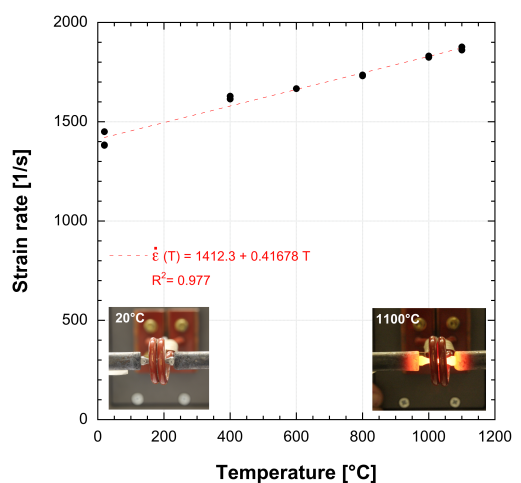

Figure 4. Input raw signals at different temperature and same initial loading conditions (a). Strain rate in function of temperature for same initial loading condition (b).

Table 2. Results at 850 1/s.

\begin{tabular}{lllll}
\hline $\begin{array}{l}\text { Temperature } \\
\left({ }^{\circ} \mathrm{C}\right)\end{array}$ & $\begin{array}{l}\text { UTS } \\
(\mathrm{MPa})\end{array}$ & $\begin{array}{l}f_{f} \\
(\mathrm{MPa})\end{array}$ & $\begin{array}{l}\epsilon_{f} \\
(\%)\end{array}$ & $\begin{array}{l}\dot{\epsilon}_{\text {eff. }} \\
(1 / \mathrm{s})\end{array}$ \\
\hline 20 & 2232 & 2009 & 5.73 & 843 \\
800 & 2198 & 1136 & 8.70 & 1161 \\
900 & 1044 & 1007 & 7.97 & 1251 \\
1000 & 964 & 891 & 10.70 & 1295 \\
1100 & 1254 & 647 & 18.13 & 1290 \\
\hline
\end{tabular}

\section{Results}

Figures $5 \mathrm{a}, 5 \mathrm{~b}$ and $5 \mathrm{c}$ show the engineering stress versus strain curves obtained in the temperature range $20-1100^{\circ} \mathrm{C}$ by imposing a preload of $26 \mathrm{kN}, 35 \mathrm{kN}$ and $50 \mathrm{kN}$ that causes at ambient temperature a strain rate of $850 \mathrm{~s}^{-1}, 1400 \mathrm{~s}^{-1}$ and $2200 \mathrm{~s}^{-1}$, respectively.

In Tables 2, 3, 4 the average results in terms of ultimate tensile strength (UTS), fracture stress $\left(f_{f}\right)$, fracture elongation $\left(\epsilon_{f}\right)$, effective strain rate $\left(\dot{\epsilon}_{e f f}\right.$. $)$ in function of temperature for the three target strain rate are resumed. In Figures $6 \mathrm{a}, \mathrm{b}$ are reported the reduction cross-area and fracture strain (a) as well as reduction factor of the UTS and fracture stress (b) in function of temperature and $14001 / \mathrm{s}$. 
Table 3. Results at 1400 1/s.

\begin{tabular}{lllll}
\hline $\begin{array}{l}\text { Temperature } \\
\left({ }^{\circ} \mathrm{C}\right)\end{array}$ & $\begin{array}{l}\mathrm{UTS} \\
(\mathrm{MPa})\end{array}$ & $\begin{array}{l}f_{f} \\
(\mathrm{MPa})\end{array}$ & $\begin{array}{l}\epsilon_{f} \\
(\%)\end{array}$ & $\begin{array}{l}\dot{\epsilon}_{\text {eff. }} \\
(1 / \mathrm{s})\end{array}$ \\
\hline 20 & 2444 & 2015 & 5.49 & 1405 \\
800 & 2245 & 1084 & 8.31 & 1733 \\
1000 & 2247 & 928 & 9.99 & 1828 \\
1100 & 1536 & 737 & 16.70 & 1868 \\
\hline
\end{tabular}

Table 4. Results at 2200 1/s.

\begin{tabular}{lllll}
\hline $\begin{array}{l}\text { Temperature } \\
\left({ }^{\circ} \mathrm{C}\right)\end{array}$ & $\begin{array}{l}\text { UTS } \\
(\mathrm{MPa})\end{array}$ & $\begin{array}{l}f_{f} \\
(\mathrm{MPa})\end{array}$ & $\begin{array}{l}\epsilon_{f} \\
(\%)\end{array}$ & $\begin{array}{l}\dot{\epsilon}_{e f f .} \\
(1 / \mathrm{s})\end{array}$ \\
\hline 20 & 2770 & 1437 & 6.7 & 2200 \\
800 & 1170 & 1120 & 6.45 & 2495 \\
900 & 1235 & 1068 & 5.7 & 2540 \\
1000 & 1351 & 902 & 10.17 & 2595 \\
1100 & 1067 & 721 & 16.07 & 2610 \\
\hline
\end{tabular}

a)
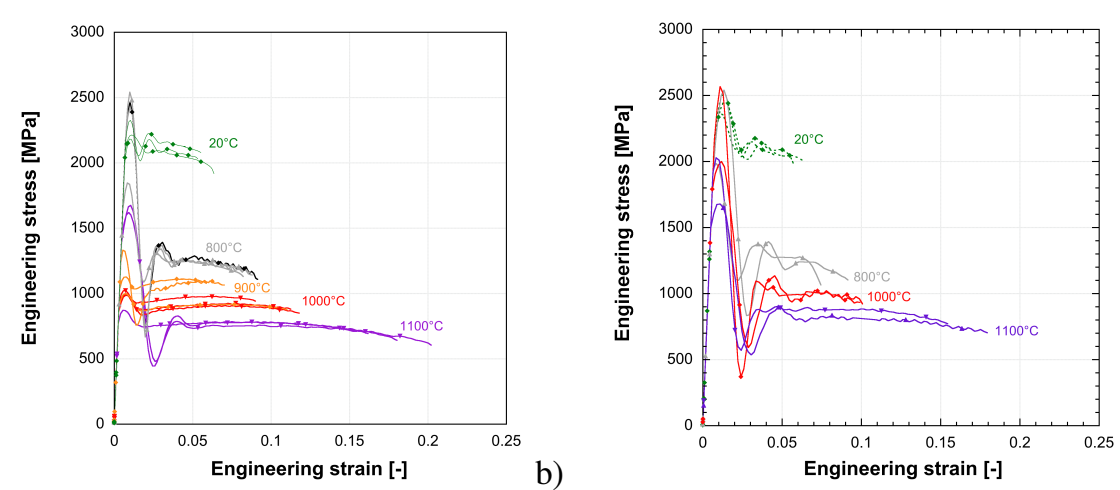

b)

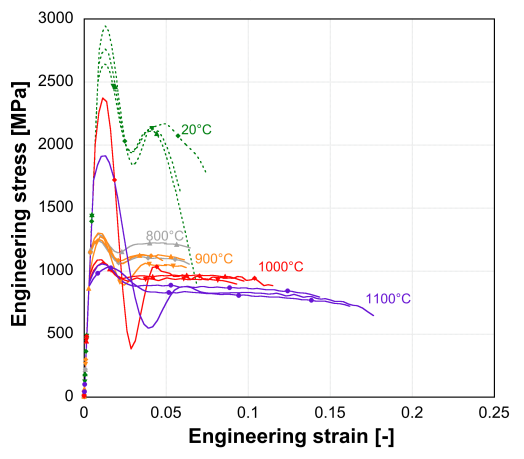

Figure 5. Stress vs. strain at different temperature and (a) 850 1/s, (b) 1400 1/s, (c) 2200 1/s. 

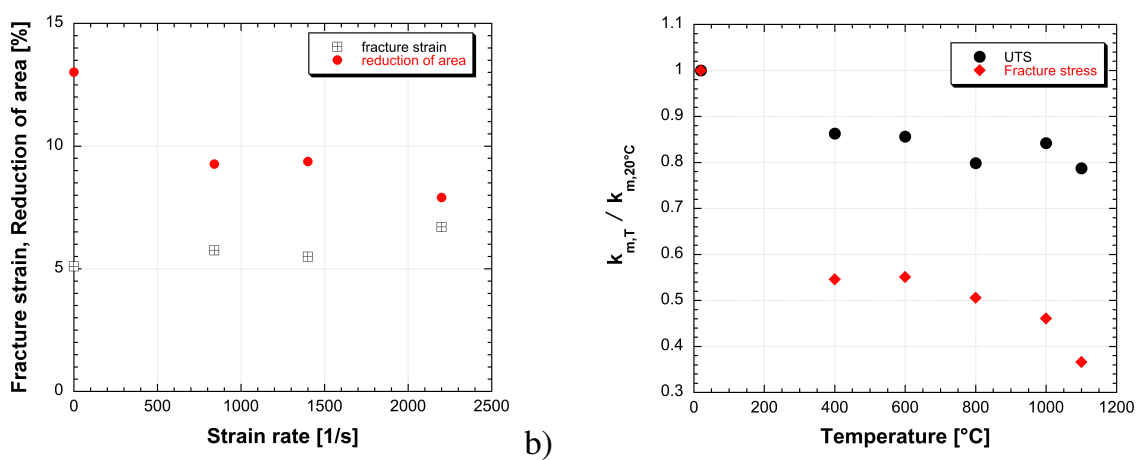

a)

Figure 6. Reduction cross-area and fracture strain (a) and reduction factor of the UTS and fracture stress (b) in function of temperature and 1400 1/s.

\section{Conclusions}

In this paper, the tensile mechanical properties and fracture behaviour of a commercial Tungsten alloy has been experimentally investigated at elevated temperature ranging from 800 to $1100^{\circ} \mathrm{C}$ in high strain-rate regime of 850,1400 and $2200 \mathrm{~s}^{-1}$. It has been found that the tensile mechanical properties such as ultimate tensile strength, fracture strength and nominal total elongation of the examined commercial tungsten alloy depend strongly on the test temperature and generally show a decreasing tendency with increasing temperature.

\section{References}

[1] Yadav S., Ramesh K.T. Materials Science and Engineering: A, 203 140-153 (1995)

[2] Rohr I., Nahme H., Thoma K., Anderson C.E. International Journal of Impact Engineering, 35 811-819 (2008)

[3] Rittel, D., Weisbrod, G. International Journal of Fracture 112 87-98 (2001)

[4] Hafizoglu H., Durlu N. International Journal of Impact Engineering, 121 44-54 (2018)

[5] Wurster S., Gludovatz B., Pippan R. International Journal of Refractory Metals and Hard Materials, 28 692-697 (2010)

[6] Mutoh Y., Ichikawa K., Nagata K. et al. J. Mat. Sc., 770-775 (1995)

[7] Gong X., Fan J., Ding F. Materials Science and Engineering: A, 646 315-321 (2015)

[8] Cadoni E., Dotta M. and Forni D. Procedia Structural Integrity 28, 964 - 970 (2020)

[9] Cadoni E., Dotta M., Forni D., Tesio N., Albertini C. Materials and Design,49 657 - 666 (2013)

[10] Cadoni E., Dotta M., Forni D., Tesio N. Materials and Structures, 48 1803-1813 (2015)

[11] Cadoni E., Singh N., Forni D., Singha M., Gupta N., The European Physical Journal Special Topics 225(2) 409-420 (2016)

[12] Singh N.K., Cadoni E., Singha M. Gupta N.K. Journal of Engineering Mechanics ASCE 139 1197-1206 (2013)

[13] Cadoni E., Dotta M., Forni D., Spaetig, P. Journal of Nuclear Materials 414360 - 366 (2011)

[14] Forni D., Chiaia B., Cadoni E., Materials and Design 94 467-478 (2016)

[15] Cadoni, E., Forni, D. Fire Safety Journal, 102869 (2019) 